\title{
The Effect of Violent Video Game Exposure on the Aggression Level of Undergraduates
}

\author{
Teoh Yee Meng, Michelle Wong Mei Xin, Goh Yi Chen, Sarvarubini Nainee* \\ Department of Psychology and Counselling, Faculty of Arts and Social Science, Universiti Tunku Abdul Rahman, Jalan Universiti, Bandar Barat, 31900 \\ Kampar, Perak. \\ *Corresponding author: sarvarubini@utar.edu.my
}

\begin{abstract}
Video game violence has seen to be one of the factors that cause aggressive behaviour and this act of aggression can be a potential source of violence. This study provide a better understanding on how video game will influence an individual level of aggression through examining the possible contributing factors such as the time spent on playing violent video game, the type of video game with violent content or non-violent content. 100 undergraduates from Universiti of Tunku Abdul Rahman Perak Campus were invited to participate in this study using convenience sampling method. This quantitative research adopted Habitual Video Gaming Violent (HVGV) questionnaire to measure the frequency of video gaming and Buss and Perry (1992) aggression questionnaire to measure the aggression level of participants. The main findings of this study were the content (violent or non-violent) of video game and the frequency of violent video game played will affect an individual's aggression level. In future research, a larger scale experiment may be carried out in different state of Malaysia and have a more diverse sample, including people of other races and ages to generate a more reliable data.
\end{abstract}

Keywords: Violent video game, aggression, frequency of violent video gaming

(C) 2017 Penerbit UTM Press. All rights reserved

\subsection{INTRODUCTION}

Video game violence has seen to be one of the factors that cause aggressive behavior. The Entertainment Software Association (ESA) reported around $80 \%$ of top selling video games are given the rating of M. Rating M stands for Mature which is defined by Entertainment Software Rating Board (ERSB) in year 2014 which contain intense violence media information that include blood, gore or even sexual content. This indicates that the exposure of violent content among gamers have been increasing dramatically. According to the annual research finding by ESA also stated that $59 \%$ of American citizens play video games which creates the fact that there are an average of 2 gamers in each household, this indicates that people having access towards mature rated games has becoming more and more convenient (The Entertainment Software Association, n.d.).

In fact the studies of violent video games on aggression have been conducted for many times. Existing studies shows that the violent video game players have higher level of aggressive compare to the non-violent video game players but only for short-term (Sestir \& Bartholow, 2010). Another study of Adachi and Willoughby (2011) also found that violent video game player have higher aggression level regardless of the gender, which mean both male and female who exposed to violent video game have higher aggression level. However violent video games have greater influence on the male players compare to female players. This is supported by the findings of Anderson and Bushman (2001) stated that male responded more aggressively than female when playing a violent video game and the reason maybe is due to male is more sensitive to the aggression cue. However these studies are conducted in western countries, the application of these finding on Asian countries is vague.

\subsection{THEORETICAL FOUNDATION OF THE STUDY}

General Aggression Model (GAM) was adapted to provide a better understanding on the influences of violent video game on aggression. Figure 1 shows the overall view of General Aggression Model (Anderson \& Carnagey, 2004) which is a multi-level model to explain how interaction of personal and environmental factors affects the aggressive behavior. The upper part of the model is the distal factors and processes while the lower part shows the proximate factors. Distal factors are developmental factors that contribute to the shaping of a person's personality, while the proximate factors are the direct causes of aggressive behavior. 


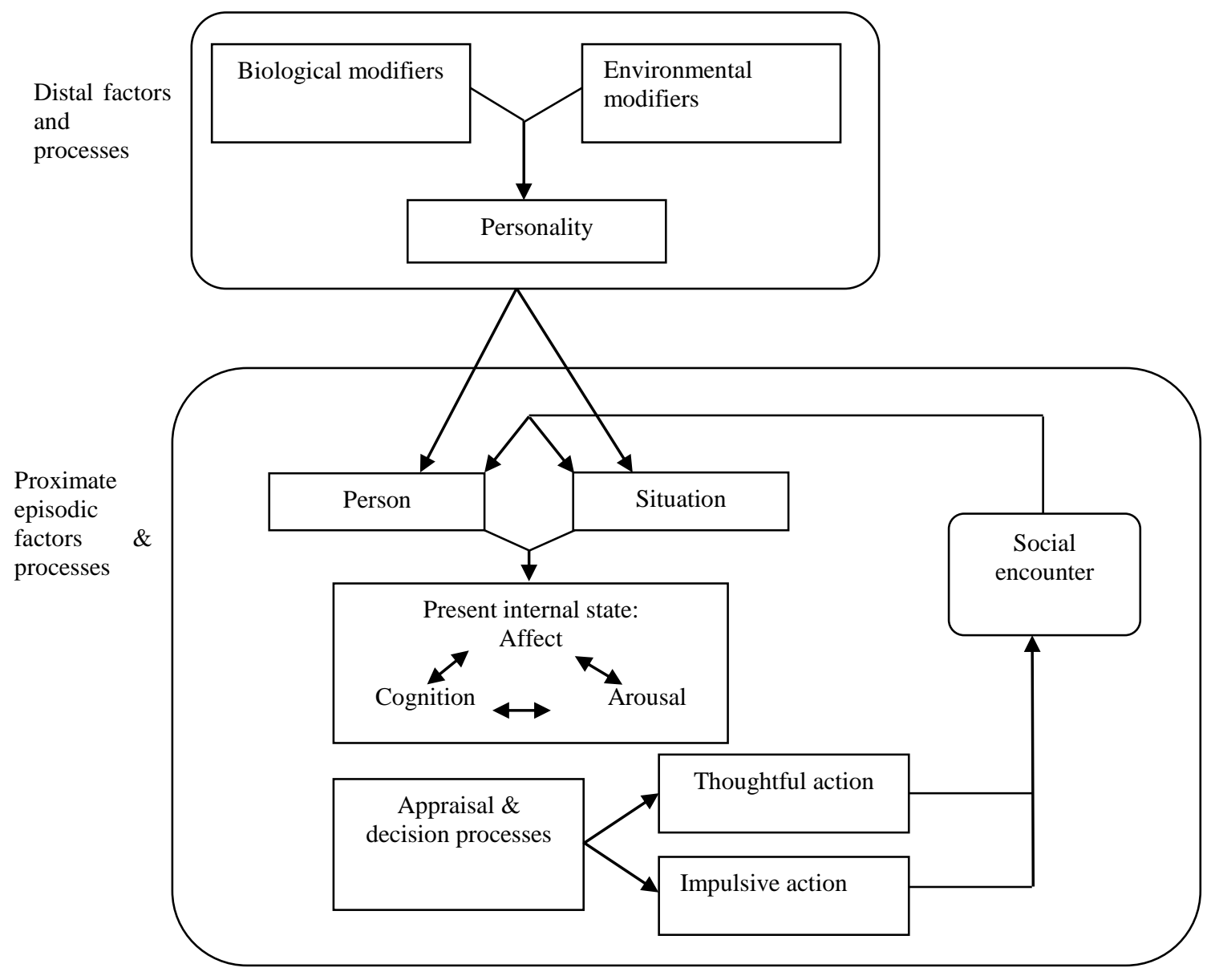

Figure 1 General aggression model

The present study focused only on the personality process of the General Aggression Model, which is shown in figure 2. Figure.2 illustrates the long-term effect of repeated exposure to violent video game. An individual have opportunity to learn aggressive behavior each time they are exposed to violent media (Anderson \& Bushman, 2001). Therefore, if an individual is exposed to violent media repeatedly, the learned knowledge is rehearsed and it becomes difficult to change. In this case, individual will view violent as normal and increase in aggressive personality. Eventually, the aggressive personality will be linked to proximate factors (personological and situational variables) and become aggressive behavior. Individual will have an aggressive outlook when link with personological variable and the social interactions will be different. Thus, the tendency of committing aggressive act in social interaction becomes higher. 


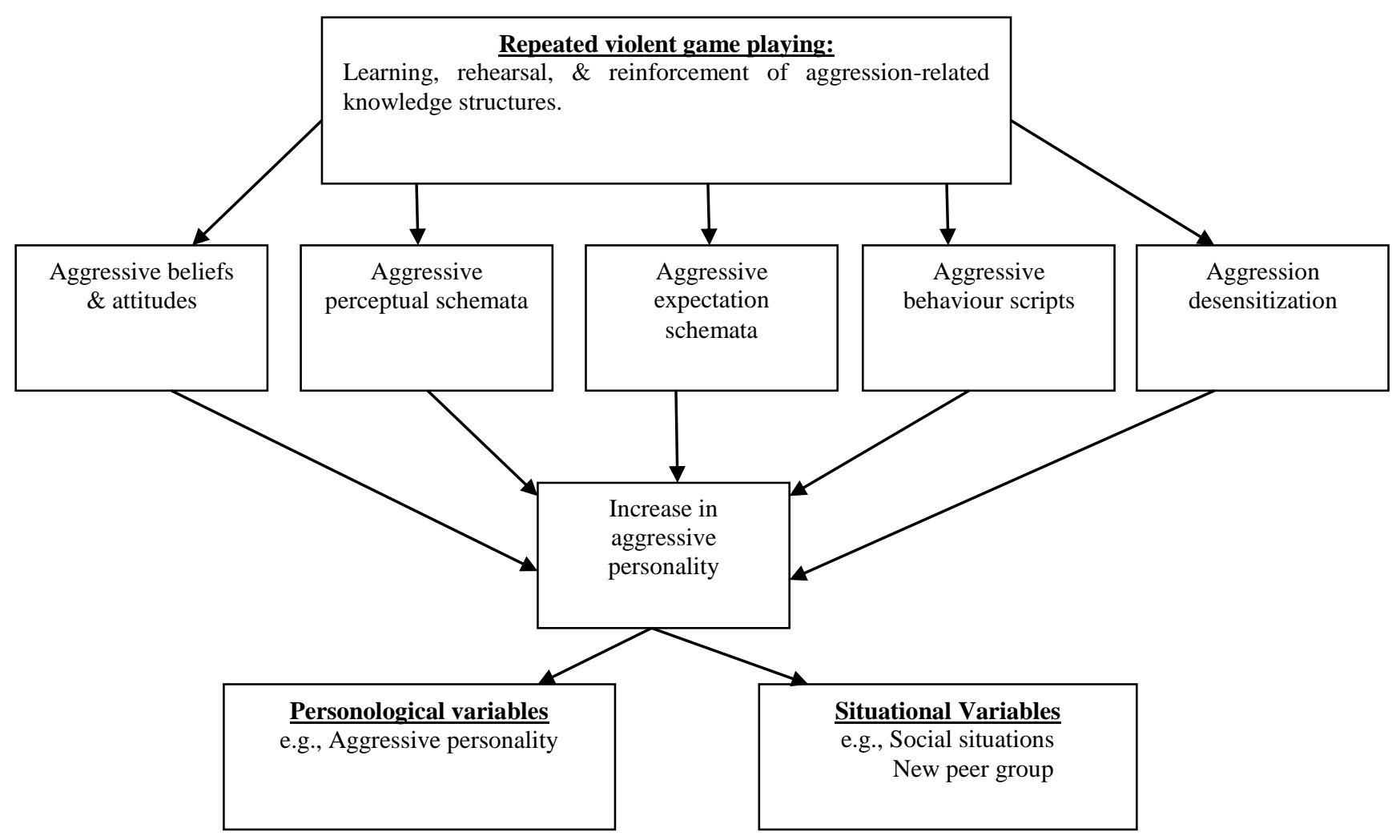

Figure 2 General aggression model (personality process)

\section{Literature Review}

\section{Content of Video Game and Aggression Level}

The quality standard of video games has been improved to become more realistic and immersive. The rise in video game quality enhances the pleasure gained through the gaming experiences of players increased and this contributed to the hypothesis that exposure to violent video games can lead to aggression. General Aggression Model (GAM) often used as a guideline in many related research to determine whether priming or desensitization is the primary route to increased aggression. This is determined by measuring startle eye blink magnitude using electromyography (EMG). An attenuated startle response represents the desensitization route while potentiated response predicts a priming route (Elmore, 2012).

The participants in this study are 77 students from the University of Missouri, Kansa city, with a mean age of 23.8 years old (Elmore, 2012). A startle eye blink magnitude was measured after participants finished their games, both violent game (Perfect Dark) and nonviolent game (Tetris). Undoubtedly, the results revealed that participants who played violent video game had attenuated startle response compared to those who played non-violent video game. The desensitization hypothesis was supported; claiming that exposure to violent video games will cause extinction of fear in reaction to violence and directly increase the level aggression.

A recent Malaysian study showed similar result, that aggressive behavior is displayed on those who played more violent video games. They took a sample of 984 high school students in Malaysia to complete a 7-point Buss-Perry scale and the video game habit questionnaires. Notably, male students from higher income background have higher chances expose to violent video games. In turn, they displayed higher degree of aggressiveness and do poor in academic achievement (Rajasakran et al., 2014).

Despite of the relationship between violent video gaming and aggression, when querying violent video game players whether they have high aggressive, most likely will be denied. This is due to the comparison of behavior in video games and their behavior in daily life (Greitemeyer, 2014). Daily behavior such as shouting at others mostly appeared to be harmless when compared with killing people in the games. When this behavior is perceived innocence, there will be fewer chances for the behavior to be ceased.

Researcher had carried out two experiments to investigate the bias in perception of aggressive behavior by playing violent video game, and the underlying effect of violent video game on aggressive behavior. In the first experiment, 82 participants with mean age 21.9 were randomly assigned to play violent or neutral games and their perception of daily life aggressive behavior were measured after that. Evidence suggested that after playing violent video game, participants' perception about owns daily life aggressive behavior have become less severe, which might sublime into real life aggressive behavior. However, when asked about perception on others' daily life aggressive behavior, it was not perceived as less aggressive. In experiment 2, there were 43 participants with mean age 31.9 years old. The experiment was a replication of experiment 1, with addition of measuring their aggressive behavior by asking them to administer hot chili sauce. A significant result showed that difference in perception of aggressive behavior underlies the effect of violent video games on actual aggressive behavior. In general, people perceived the severity of aggressive by their past experience. If an impulsive act is viewed as harmless compared to killing people in video games, individual will have a great chance carrying out that act. 
However, a contradict result was shown by Prokarym (2012) in his study among undergraduate students from the University of Texas. His study aimed to find out is there any influence of video game play on aggressive personality and how does the content of game (violent or non-violent) affect aggressive personality. The final result suggests that there is no significant effect of video game content on individuals' aggressiveness. Justification provided by the researcher was that, this study was a survey research and unlike other experimental studies, this study cannot examine the immediate effect of video game played. Adachi and Willoughby (2011) suggested that to examine a precise relationship between violent video game and non-violent video game in aggression level, competitiveness, difficulty, and pace of action of the games have to be taken into account.

Generally, violent video games were trusted to be more competitive and difficult than non-violent video games (Adachi \& Willoughby, 2011). Therefore, the characteristic of the games, such as competitiveness, difficulty, and pace of action should be controlled to avoid confounding variables which will affect the results. For example, in terms of competitiveness, using car racing game is more appropriate than The Sim City series for non-violent video gaming experience.

\section{Content of Video Game and Aggression Level}

In past research there is a lot of finding in relationship of the habitual video game violence also known as the frequency of violent video gaming and aggression level. According to Krahe and Moller (2010) findings found that there is significant relationship between exposure to violent media and aggression behavior. The evidence shows that higher exposure to violent media significantly predicted physical aggression but no significant relationship found between violent media and relational aggression. Academic performance if found to be negatively correlated with an individual aggression level. Moreover, the repeated exposures to violent media diminish empathy level of an individual. Individual with low existing aggression level increase over period when repeated exposed to violent video media, but it does not affect the individual with high existing aggression level.

Earlier study indicated that males are more likely to be engaged in violent video game compared to female. Besides that the gender show differences in aggression type, which male is more towards physical aggression and female is more towards hostility. Even though both gender engaged in violent video game usage male are predicted to have higher aggression than female. More importantly, the study found that adolescent tend to engage in aggressive behavior when they are constantly expose to the violent video game even the individual with low level of hostility (Kumarasuriar et al., 2011). Besides that another existing literature stated that participants who play violent video game send a longer duration and higher intensity of noise blast as punishment which is indicated as aggression behavior. As the participants continues to play violent video game for each day, they become even aggressive. On the other hand, participants who play non-violent video game do not show increase in aggression behavior.

Further evidence have been found by the research of Gentile et al. (2014), that they wish to find out whether the cognitive or emotional variables mediate the effect of violent video game play on aggression level. Data are collected through 3034 children and adolescent from secondary school and primary school in Singapore. The result shows that increase in frequency of violent video game play lead to higher aggressive cognition which result in higher aggressive behavior. The increase in aggressive behavior is mostly relying on the level of aggressive cognition. Genders do not show any significant differences in aggressive behavior. The research found that the violent video game have larger impact on younger individual in aggressive cognition. Besides, the exposure to violent media influences both individual with high existing aggressive level and low existing aggressive level, but the influences on high existing aggressive level is more powerful. Although involvement of parents are believed to have great influences on children behavior, but the result shows that it does not influence the path of violent video game play lead to aggressive cognition and result in aggressive behavior.

However there are also findings that do not support the relationship of exposure to violent video game and aggression level by using hostility to measure aggression level (Valadez and Ferguson, 2012). Similar to the other research video game habits questionnaire is given to participants to identify the frequency of playing video game and the violent content of the video game. Next, participants have to complete the paced auditory serial-addition task (PASAT) adopted from Gronwall (1977) and they are blinded to the real purpose of the study by telling them this memory test. PASAT is a computer program that require participant to add numbers from 1 to 20 , the program will speak a digit in every few second, each digit have to be sum up with the previous digit speak by the program (Gronwall, 1977). Purpose of the program is to causes irritation, frustration and anxiety in participants through interference effect (Valadez \& Ferguson, 2012). After PASAT, participants are given a State Hostility Scale adopted from Anderson, Deuser, and DeNeve (1995) which contain 35 items to assess participant's mood as post-test, this is to measure the current hostility level of the participants. Later, participants are given either violent or non-violent game for either $15 \mathrm{~min}$ or $45 \mathrm{~min}$ based on the randomize decision of a program. Lastly, participant requires filling up the State hostility test again as post-test to identify whether the video game play session have increase the hostility feeling of participants or not. Despite the amount of time play hostility level show no differences in participants who play violent game and participants who play violent game. Moreover, the irritation level of participant is more likely to be reduce when researcher give them more time to familiar with the controls. This result less irritation during the video game session which caused by unfamiliar with the game controls. The study concludes the amount of time spent on the violent or non-violent video game do not affect the hostility level of individual. Nevertheless, the amount of time spending on violent video game is arguably short to invoke the effect of aggression.

\subsection{CONCEPTUAL FRAMEWORK}

In this study, the researcher investigated two types of variables as shown in figure 3 . These variables include the content of video games and the frequency of video games played. The content of the video games (violence / non-violence), determines the message and information sent from the video game to the user. The second variable is the frequency of the gameplay which can be measured by amount of time used for gaming per day. Higher frequency increases the chances of rehearsing violent behaviors virtually which is associated with aggression. Anderson and Bushman (2001) proposed that repeated exposure to violent video game will increase a person's aggressive behavior and decrease prosocial behavior in various situations. Hence, there were two hypotheses. First hypothesis, there is a significant difference between content (violent and non-violent) video games and aggression level. Second hypothesis, there will be a significant relationship between habitual video game violence (HVGV) and aggression level. 


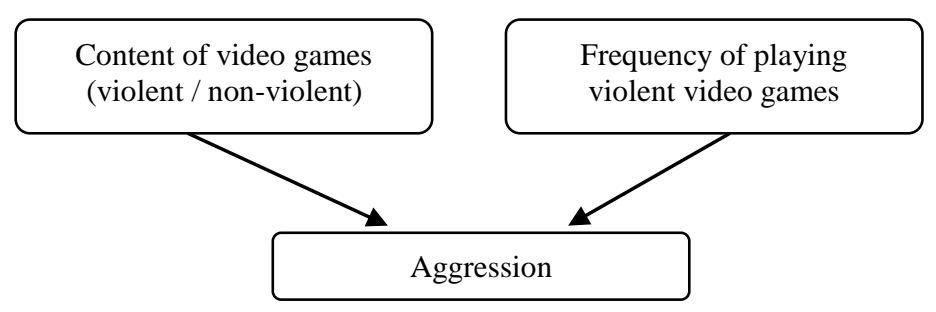

Figure 3 Conceptual framework

\subsection{METHODOLOGY}

\section{Research Design}

This research adopted quantitative research design whereby self-administered questionnaire were given to partipants. Convenience sampling method was used and the reason of using convenience sampling is because of the cost effectiveness and time efficient, which it allows to lower our research cost and save the time of research.

\section{Research Sample}

Total of 100 undergraduate students of University of Tunku Abdul Rahman participated in this research. Participants are undergraduates from the University of Tunku Abdul Rahman Perak Campus. The age range of participants was from 18 to 25 . Participants are from various field of study and consist of 72 males and 28 females.

\section{Research Instrument}

Self-administered questionnaire were used to collect data. The questionnaire contained three part, demographic details of participants, habitual video game violent and Buss and Perry (1992) aggression questionnaire. All questions in the questionnaire were in English. Demographic part requires respondent information such as age, gender, and field of study.

Habitual Video Gaming Violent (HVGV: Kumarasuriar, Pangiras, Sinnapan, \& Koran, 2011). HVGV have been adopted in this study to measure the frequency of the violent video game play. HVGV consist of 9 items. Participants are required to list down three games that they have played the most recently and then rate for the violent content of each game they have listed with the given Likert scale from 1 to 5. The response ranged from 1(Strongly agree) to 5(Strongly disagree). The score is calculated by multiplying the score of three violent contents of the games and averaging them. The result of higher score indicates the higher exposure rate.

Buss and Perry Aggression Questionnaire (Buss \&Perry, 1992). Buss and Perry Aggression Questionnaire was used to measure the aggression level of participants. The questionnaire consists of 29 items with Likert scale from 1 to 5, extremely uncharacteristic of me to extremely characteristic of me. Buss and Perry Aggression Questionnaire measure aggression level in four sub scales, physical aggression, verbal aggression, anger and hostility. Question 1 to 9 designed to measure the physical aggression, follow by question 10 to 14 designed to measure the verbal aggression, next question 15 to 21 designed to measure anger and question 22 to 29 designed to measure the hostility. For physical aggression and anger subscale, the scoring method is reversed which means the participants choose first choice will get 5 marks instead of 1 mark. Buss and Perry (as cited in Anderson \& Dill, 2000) reported the reliability of the aggression questionnaire at alpha Cronbach's coefficient $\alpha=.89$ and a test-retest reliability at .80 .

\subsection{RESULTS AND DISCUSSION}

\section{Hypothesis 1}

Hypothesis 1: There is a significant difference between content (violent and non-violent) video games and aggression level.

Table 1 Independent Sample T-Test of Aggression level among violent and non-violent video game

\begin{tabular}{|c|c|c|c|c|c|c|c|c|}
\hline & \multicolumn{4}{|c|}{ Content } & \multirow[b]{3}{*}{$d f$} & \multirow[b]{3}{*}{$t$} & \multirow[b]{3}{*}{ 95\% CI for Mean Difference } & \multirow[b]{3}{*}{$\mathrm{p}$} \\
\hline & \multicolumn{2}{|c|}{ Violent } & \multicolumn{2}{|c|}{ Non-Violent } & & & & \\
\hline & $M$ & $S D$ & $M$ & $S D$ & & & & \\
\hline $\begin{array}{c}\text { Aggression } \\
\text { level }\end{array}$ & 81.86 & 21.84 & 65.80 & 16.35 & 98 & -4.20 & $-23.65,-8.48$ & $.031 *$ \\
\hline
\end{tabular}


An independent t-test was conducted to compare the relationship between video game content (violent and non-violent) and aggression level among UTAR students. The result shows there is a significant difference in aggression level between the violent game and nonviolent game, $\mathrm{t}(98)=-4.20, \mathrm{p}<0.05$ as shown in Table 1 . Violent games had a higher level of aggression $(\mathrm{M}=81.86, \mathrm{SD}=21.84)$ than non-violent game $(\mathrm{M}=65.80, \mathrm{SD}=16.35)$. This result suggests that video game content have an impact on the aggression level of the users. Therefore, we accept the hypothesis that there is a significant difference in aggression level between violent and non-violent game. Adachi and Willoughby (2011) carried out a study among university students in Ontario, Canada to examine the influence of games content towards aggression level. The result indicates that violent video game player have higher aggression level regardless of the gender. The violent content of video game has proven many times to be one of the factors that cause aggressive behavior among youngsters (Anderson et al., 2007).

According to General Aggression Model (GAM), an individual tend to observe the behavior of their surrounding and imitate them, the more frequent the action is repeated the higher the chances of imitation to occur. The nature of violent game with repeated fictional social encountered condition elements influence the players to learn and imitate unintentionally based on the choices the video games (Anderson \& Bushman, 2001). Furthermore, Elmore (2012) in his article stated that due to the advancement of the current technology, video games graphics has enhanced into a newer level, making the gaming experience more realistic and immersive, increasing the impact of the experience at the same time desensitization occurs, claiming that exposure to violent video games will cause neglecting of fear towards violence thus directly increase the level aggression.

However, Sestir and Bartholow (2010) in their study among 188 undergraduates at University of North Carolina at Chapel Hill stated that the content of the media only have a short term effect on the individual aggressive level. In addition, a recent study by Greitemeyer (2014) also indicated that it is not necessary that playing violent video games has a direct impact towards our aggressive behavior. He further explains that it is irrelevant to compare a real life behavior with a behavior in video games.

Hypothesis 2

Hypothesis 2: There will be a significant relationship between habitual video game violence (HVGV) and aggression level.

Table 2 Pearson correlation of relationship between HVGV and aggression level

\begin{tabular}{llll}
\hline & & HVGV & Aggression \\
\hline \multirow{3}{*}{ HVGV Score } & Pearson Correlation & 1 & $.406^{* *}$ \\
& Sig. (2-tailed) & & .001 \\
& $\mathrm{~N}$ & 100 & 100 \\
\hline
\end{tabular}

**. Correlation is significant at the 0.01 level (2-tailed).

A Pearson Correlation Coefficient was computed to assess the relationship between HVGV score and aggression level. Table 2 presents the correlation test and it is found that there was an association between the two variables, $r=0.406, n=100, p<0.001$. Thus, the hypothesis is accepted. The value of $r=0.406$ indicates a strong positive relationship between the two variables.

The finding was consistent with study of Krahe and Moller (2010) that shows that exposure to the violent media has a significant relationship with aggression behavior. The high violence media usage will lead to increasing of physical aggression of an individual. When observe the relationship in reverse way there is not enough evidence to claims that higher physical aggression individual will have higher violence media usage. The individual that low in initial aggression level is more vulnerable to aggression thoughts after interaction with violent media. However, if the initial aggression level was high the media violence usage may not contribute to the increase in aggression.

Furthermore, the finding was consistent with a study by Kumarasuriar et al. (2011) among Malaysian adolescent between the age group of 13-17. The result indicates that aggressive behaviors are influenced by the exposure rate to the violent video game. Hence, the trend is not only noticeable in western culture but also in local context. Gentile et al. (2014) pointed out that the influence of violent video game in aggression level for both primary and secondary school students is significant but primary students demonstrate stronger influence by violent video game. This can be explained by the General Aggression Model, the repeated exposure to violent video game will reinforce the aggression thoughts. Thus the earlier exposure to violent video game will result in higher level of aggression.

Conversely, there was another research conducted on university students by Valadez and Ferguson (2012) which brings a contradict findings. The result does not show significant relationship in between aggression level and exposure to violent video game. The likelihood of this occurs is due to the method of conducting research. The participants aggression level is assess after they play the violent video game for 45 minutes, which is not enough to show the effect of violent video games. According to General Aggression Model, the accumulated aggression thoughts from repeated exposure to violent video game increase the aggression level of individual.

\subsection{CONCLUSION}

The spring up of violent games can be a problematic issue as aggression level in individual rises can be a forewarning for violence act. This research focus on the two aspects that have high possibility in increasing aggression level, which are the content (violent and nonviolent) of video games and the frequency of violent video game played. An independent sample t-test shows that the content of video games influence the aggression level as the General Aggression Model (GAM) proposed, the more the learned action is rehearsed, there will be a high chance that gamers will imitate the violence behavior unconsciously. The frequency of violent video game played has a positive correlation with aggression level, which means that exposure to high violent media influence the level of aggression in gamers. In future research, a larger scale experiment may be carried out in different state of Malaysia and have a more diverse sample, including people of other races and ages to generate a more reliable data. Moreover, a lab experiment should be carry to measure the aggression level of an individual able to generate more reliable result instead of using self-administered questionnaire. 


\section{References}

Adachi, P. J., \& Willoughby, T. (2011). The Effect Of Violent Video Games On Aggression: Is It More Than Just The Violence?. Aggression and Violent Behavior, $16(1), 55-62$

Anderson, C. A., \& Bushman, B. J. (2001). Effects of Violent Video Games On Aggressive Behavior, Aggressive Cognition, Aggressive Affect, Physiological Arousal, And Prosocial Behavior: A Meta-Analytic Review Of The Scientific Literature. Psychological science, 12(5), 353-359.

Anderson, C. A., \& Carnagey, N. L. (2004). Violent Evil And The General Aggression Model. The Social Psychology Of Good And Evil, 168-192.

Anderson, C. A., Deuser, W. E., \& DeNeve, K. M. (1995). Hot Temperatures, Hostile Affect, Hostile Cognition, And Arousal: Tests Of A General Model Of Affective Aggression. Personality and Social Psychology Bulletin, 21(5), 434-448.

Anderson, C. A., Gentile, D. A.. \& Buckley, K. E. (2007). Violent Video Game Effects On Children And Adolescents. New York: Oxford University Press.

Buss, A. H., \& Perry, M. (1992). The Aggression Questionnaire. Journal Of Personality And Social Psychology, 63(3), 452.

Elmore, W. R. (2012). The Effect Of Violent Video Game Play On Emotion Modulation Of Startle (Doctoral dissertation, University of Missouri--Kansas City).

ESRB ratings guide. (n.d.). Retrieved October 29, 2014, from http://www.esrb.org/ratings/search.jsp

Gentile, D. A., Li, D. D., Khoo, A., Prot, S., \& Anderson, C. A. (2014). Mediators and Moderators of Long-term Effects of Violent Video Games on Aggressive Behavior: Practice, Thinking, and Action. JAMA Pediatr, 168(5), 450-457.

Greitemeyer, T. (2014). Intense acts of violence during video game play make daily life aggression appear innocuous: A new mechanism why violent video games increase aggression. Journal of Experimental Social Psychology, 50, 52-56.

Gronwall, D. M. A. (1977). Paced Auditory Serial-Addition Task: A Measure Of Recovery From Concussion. Perceptual and motor skills, 44(2), $367-373$.

Krahé, B., \& Möller, I. (2010). Longitudinal Effects Of Media Violence On Aggression And Empathy Among German adolescents. Journal of Applied Developmental Psychology, 31(5), 401-409.

Kumarasuriar, V., Pangiras, G., Sinnapan, S., \& Koran, S. (2011). A Study of the Relationship between Violent Video Game Playing and Aggression among Adolescents in the Klang Valley, Malaysia. International Proceedings of Economics Development \& Research, 20.

Prokarym, M. (2013). The Effect Of Video Games On Aggressive Behavior In Undergraduate Students.

Rajasakran, T., Wong, A. K., Sinnappan, S., Kumarasuriar, V., Pangiras, G., \& Koran, S. (2014). Aggressor Games: Of Violent Video Games and Aggression among Higher-income Group Schoolchildren in Malaysia. Science Technology \& Society, 19(3), 383-398.

Sestir, M. A., \& Bartholow, B. D. (2010). Violent and Nonviolent Video Games Produce Opposing Effects On Aggressive And Prosocial Outcomes. Journal of Experimental Social Psychology, 46(6), 934-942.

Valadez, J. J., \& Ferguson, C. J. (2012). Just a Game After All: Violent Video Game Exposure And Time Spent Playing Effects On Hostile Feelings, Depression, And Visuospatial Cognition. Computers in Human Behavior, 28(2), 608-616. 